\title{
Organising the MRCPsych Part Il examination
}

\author{
D. F. O'Sullivan, Senior Registrar; N. M. J. KenNedy, Registrar; and R. Jenkins, \\ Registrar, Academic Unit, All Saints Hospital, Lodge Road, Winson Green, \\ Birmingham B18 5SD
}

The MRCPsych Part Il examination takes place twice a year at a number of centres in Britain and Ireland. It comprises five components. Three are written exercises and the other two, a viva voce and a clinical examination, are practical assessments characterised by face-to-face interaction with the examiners.

The aim of this paper is to provide a stepwise guide to the organisation of the practical components. The rationale for doing so is our belief that it is essential that the mechanics of the examination run smoothly if candidates are to be facilitated in doing themselves justice on the day. Our views are based on our experience of organising the examination and feedback from participants. It is intended to build on previous observations (Armstrong \& Loosemore, 1988).

\section{The objective}

Fourteen candidates a day have both a clinical and a viva examination. The clinical consists of an interview with a patient lasting one hour, followed by a 30 minute presentation to two examiners, during part of which time the patient is again interviewed by the candidate. The viva lasts for 30 minutes and involves a second pair of examiners.

In Birmingham, the examinations run over two days and involves 28 patient interviews. The ideal situation is to ensure the smooth running of the examinations without causing undue distress to patients, candidates or examiners. If possible, the examination should be a positive experience for all.

\section{The setting}

The ideal examination centre is quiet and easily accessible, with clinical activities suspended for the duration of the examination. Where two clinical and two viva tables are in operation, a total of 12 rooms will be required. There should be two large waiting rooms for candidates and patients whose ambience is as pleasant as possible. It is unreasonable to expect large groups of anxious people to endure a small, poorly ventilated room. In our experience patients appreciate a television in their waiting area. Toilet facilities should be abundant and clean. Four rooms are required for the candidates to undertake the clinical interview. These should be of sufficient size to accommodate a desk, two chairs, examination couch and appropriate equipment. Four examination rooms are needed with appropriate space and furnishings for two examiners, the candidate, the patient and the College observer, if present. A smaller waiting room adjacent to the examiners is necessary for the patients waiting to be called in to meet the examiners and candidate together. The corridors of the centre will need to be sufficiently wide to allow for a chair outside each of the examination rooms for the candidates to wait prior to their ordeal. Finally, it is of vital importance to have a co-ordination centre where the organisers can keep an eye on things and where timetables, notes and summaries can be safely stored.

\section{The staff}

\section{The Senior Organiser}

\section{Main functions:}

(a) College liaison

(b) identification and availability of centre

(c) appointment of the organiser

(d) appointment of reception and nursing staff

(e) candidate identification

(f) host to examiners

(g) payment to patients.

The Senior Organiser is also in a position to put candidates at their ease. At an early stage, she/he should arrange catering for the examiners and organisation team, and prepare a list of hotel details for candidates and examiners.

\section{The Organiser}

Main functions:

(a) arrange stewards

(b) request case summaries

(c) arrange adequate patient numbers

(d) co-ordinate timetables

(e) rectify problems arising on the day

(f) arrange catering and transport for patients

(g) host to candidates and patients.

Normally a senior registrar, the organiser arranges the required two stewards for each day and ensures a 
plentiful number of patients to allow for illness or change of mind (one caveat we add is that transport is usually the most frequent source of problems on the day).

\section{The stewards}

Main functions:

(a) adhere to timetables

(b) match candidates with patients/examiners

(c) host to candidates and patients.

\section{The nurse}

Main functions:

(a) ensures comfort and safety of patients

(b) arranges catering as required

(c) returns patients to wards.

The receptionist

Main functions:

(a) greets arrivals

(b) directs to appropriate waiting rooms

(c) provides good quality refreshments.

\section{Preparation prior to examination}

(a) The Senior Organiser identifies an organiser with sufficient notice - at least four weeks.

(b) The Organiser identifies two stewards who can be available (they must be members of the College).

All require to be free of clinical commitments on the required days.

(c) The Organiser circulates requests to medical colleagues for patients and case summaries, outlining the dates of the examinations, guidelines for the type of patient and nature of information required. Details of payments should be provided to whoever prepares the summaries and for the secretaries who typed them. An information sheet for patients, explaining the examination, and what will be expected of them, how long they will be required for, and including details of payment are also provided.

Guidelines are provided on the type of patient and the case summary. Feedback from examiners suggests that more detailed summaries of two sides of A4 or more are preferred. The date on which the mental state was assessed should be recorded. The organiser should approach colleagues three weeks before the exams to request that summaries be prepared a week prior to the event (to ensure that minds are concentrated on the task). In reality, it will not be until the day before the examination that sufficient sum- maries will be available and then, only after many personal approaches to colleagues! As the number of patients available in many hospitals is insufficient to provide adequate numbers, approaches may have to be made to other units. The Organiser should enlist a colleague at each of these hospitals to coordinate the arrangements for nursing escorts, transport and case notes required on the day. (The College should note that with more community care, other hospitals may well find themselves being more frequently asked to give assistance to examination centres with a resultant increase in expenditure). One patient is required for each candidate and one reserve required for every four patients who take part.

On the eve of the examination the Senior Organiser and Organiser ensure that the centre is appropriately furnished and that the interview rooms are equipped with stethoscope, sphygmomanometer, ophthalmoscope and CNS examination tray-in working order and with spare batteries available. A working timetable with patients assigned to candidate numbers should be prepared (see Table I). Patients should be visited by a member of the organising team before the examination if possible.

\section{The day of the examination}

(a) The Senior Organiser and Organiser ensure that the centre is clearly signposted.

(b) Timetables with names of examiners and names and numbers of candidates are clearly posted.

(c) Patients are allocated to examination numbers; case summaries are marked with the associated number and made available to the examiners together with the casenotes.

(d) The Organiser telephones any external centres providing patients (who should all be scheduled for the latter part of the examination, as should any out-patients) to ensure all arrangements are in place.

(e) The receptionist arranges refreshments for all arrivals

(f) The organisational team meets the examiners and the stewards ascertain the examiners' preferences as to time signalling arrangements.

(g) The Senior Organiser checks the identity of the candidates as they arrive, and ensures that candidates are not known to the examiners.

(h) The examination proceeds, co-ordinated by the stewards, with the Organiser greeting 
TABLE I

Master timetable for clinical examination. Date.....

\begin{tabular}{|c|c|c|c|c|c|c|c|c|c|}
\hline $\begin{array}{l}\text { Candidate } \\
\text { number }\end{array}$ & $\begin{array}{l}\text { Patient's name } \\
\text { \& location }\end{array}$ & Table & Room & Cand. - Pt. & $\begin{array}{c}5 \min \\
\text { reminder }\end{array}$ & Pt. out & $\begin{array}{c}\text { Cand. } \\
\text { examiners }\end{array}$ & $\begin{array}{l}S \min \\
\text { reminder }\end{array}$ & Cand. out \\
\hline $\begin{array}{l}501 \\
502 \\
503 \\
504 \\
505 \\
506 \\
507 \\
508 \\
509 \\
510 \\
511 \\
512 \\
513 \\
514\end{array}$ & $X$ Ward $Y$ & $\begin{array}{l}\text { A } \\
\text { B } \\
\text { A } \\
\text { B } \\
\text { A } \\
\text { B } \\
\text { A } \\
\text { B } \\
\text { A } \\
\text { B } \\
\text { A } \\
\text { B } \\
\text { A } \\
\text { B }\end{array}$ & $\begin{array}{l}\text { A1 } \\
\text { B1 } \\
\text { A2 } \\
\text { B2 } \\
\text { A1 } \\
\text { B1 } \\
\text { A2 } \\
\text { B2 } \\
\text { A1 } \\
\text { B1 } \\
\text { A2 } \\
\text { B2 } \\
\text { A1 } \\
\text { B1 }\end{array}$ & $\begin{array}{r}8.55 \\
8.55 \\
9.35 \\
9.35 \\
10.25 \\
10.25 \\
11.05 \\
11.05 \\
12.55 \\
12.55 \\
1.35 \\
1.35 \\
2.15 \\
2.15\end{array}$ & $\begin{array}{l}\text { Yes } \\
\text { Yes } \\
\text { No } \\
\text { Yes } \\
\text { etc. }\end{array}$ & $\begin{array}{r}9.55 \\
9.55 \\
10.35 \\
10.35 \\
11.25 \\
11.25 \\
12.05 \\
12.05 \\
1.55 \\
1.55 \\
2.35 \\
2.35 \\
3.15 \\
3.15\end{array}$ & $\begin{array}{r}10.00 \\
10.00 \\
10.40 \\
10.40 \\
11.20 \\
11.30 \\
12.10 \\
12.10 \\
2.00 \\
2.00 \\
2.40 \\
2.40 \\
3.20 \\
3.20\end{array}$ & $\begin{array}{l}\text { Yes } \\
\text { No } \\
\text { Yes } \\
\text { No } \\
\text { Yes } \\
\text { No } \\
\\
\text { etc. }\end{array}$ & $\begin{array}{r}10.30 \\
10.30 \\
11.10 \\
11.10 \\
12.00 \\
12.00 \\
12.40 \\
12.40 \\
2.30 \\
2.30 \\
3.10 \\
3.10 \\
3.50 \\
3.50\end{array}$ \\
\hline
\end{tabular}

These times adapted from official College timetable presented to examination centre

patients as they arrive and acting as "troubleshooter'.

(i) The day proceeds more smoothly if one steward supervises the Clinical and the other the Viva Voce. It should be noted that the former is by far the more onerous task.

(j) Refreshment breaks should be rigidly adhered to if irrecoverable delays with attendant distress to all concerned are to be avoided.

(k) Once patients have completed their part of the examination they should be thanked and paid. Patients may well enquire whether they have performed appropriately at this stage and should be reassured.

(l) As soon as reserve patients are no longer required they should be paid and thanked for their willingness to assist.

(m) The organising team should endeavour to obtain feedback from all participants for future reference.

The master timetable is probably the key to the entire proceedings. If this is properly prepared, even a steward drafted in as a last-minute replacement should have no major difficulties.

\section{And after...}

The Organiser should remember that his/her responsibilities do not end with the examination.

(a) A letter to colleagues thanking them for their assistance is usually appreciated.

(b) Patients should be thanked in writing for their assistance. Emphasis that the patient has met the expectations of all concerned, and that the examination has been an overall success, appears to be welcomed.

(c) It is important that all payment forms are completed and returned to the Senior Organiser for forwarding to the College.

\section{Conclusion}

The undertaking of the organisation of the practical element of the MRCPsych Part II is one which begins well before the examination day itself. We have offered a systematic approach to the arrangements based on our experiences, and refined by helpful comments from all involved during the process, including participating patients, and colleagues not directly involved on the examination day. In particular, we noted the invaluable nature of a clearly defined working timetable, well set out and available for the organisers and stewards to scrutinise in advance of the day itself. The authors also found their experiences at locally arranged 'examination practice days', run strictly along College examination lines, helpful in planning the arrangements for the Part II itself. Clarity in communication, advance consideration and personal approaches to both colleagues and participant patients all contributed to developing a system with few untoward happenings. While acknowledging that when dealing with human beings, no system is foolproof, it is hoped that the experience of the authors will be found helpful by other examination organisers in achieving the aim of a 
"smoothly run exercise causing minimal distress", not least for the organising team.

\section{Acknowledgement}

Dr T. El-Gohary who first devised the timetable.

\section{Reference}

ARMstrong, D. \& LOOSEMORE, S. (1988) How to plan the MRCPsych Part II examination: organising the clinical examination without affecting your mental health. Bulletin of the Royal College of Psychiatrists, 12, 229-230.

\title{
Quality thinking and a formula they can't refuse ${ }^{1}$
}

\author{
Nick ChILD, Consultant Child and Adolescent Psychiatrist, Child and Family Clinic, \\ 41 Airbles Road, Motherwell ML1 2TJ
}

In the peripheries of excellence, ${ }^{2}$ providing a service is the main task. Professor Nichol says that describing a child psychiatry service to managers is easy (Third Section Newsletter). I say it is and it is not. The way he does it follows the traditional bioscientific medical pattern and logic-number and range of cases and diagnoses etc. Health managers at a first glance may be quite happy with this 'biomedical'looking picture. But I believe that in their second glance they can tell that these expensive child psychiatrists, who just sit in rooms talking, are not dealing with the same thing as surgeons and physicians.

The manager's suspicious subliminal logic may go: "If the 7,500 (or whatever) children with psychiatric disorder in a district population are in the same category as biomedical problems like fractures and infections, there would be a lot more public fuss if nine out of ten cases were not even seeing, let alone being cured by, a child psychiatrist. And they say the disorders are multifactorial, so they can just as well be dealt with by other (less expensive) health professionals or - even better - another agency or authority altogether. We have certainly not got funds for ten times the number of child psychiatrists. In fact, if nothing serious happens to the nine out of ten kids who do not see a child psychiatrist, perhaps the one in ten does not need one either. Perhaps we do not really need any child psychiatry service."

Thus the easy medical-style could cook our goose. Of course, there is no rule that says doctors must only help people with biomedical conditions. But that is the rule our medical empire has pushed strongly into place. And child psychiatrists are the worst, without endless futile ${ }^{3}$ multi-axial attempts to label everything that moves as part of International Classifications of Diseases! Yet in our clinics and research, we know that the final loading of the dice that throws up psychiatric disorder is not "biomedical" but to do with "predicaments" and personal relationships, especially those in the family." However, because someone may think a biomedical physical or mental illness may be the explanation, there is still an essential place for a doctor's authority in diagnosing 'health' or the limits of any 'disease' present. Only a doctor has the skill to contribute authoritatively in this issue. ${ }^{5}$ This notional position (of diagnosing 'health') would be nothing special if it was not accompanied by offering skilled help to work out what else the problem could be, and be helped by and this should not then be called something vaguely medical and mystifying like such-and-such a 'therapy'.

Explaining all this complexity can begin with the usual data, thus:

"There are an estimated 7,500 children and adolescents per 200,000 population disturbed enough to fit an objective definition of psychiatric disorder. Psychiatric disorder is well known to be multi-factorially produced, but the key factor is equally well known to be family factors and functioning. Directly involved with worrying and responsibilities for these 7,500 children will be their families (nuclear, extended and substitute). That is another 20,000 close family members involved in these cases. It is also well-known that other members of such families have a high proportion of related physical, mental and social disorder and will be attending relevant helping professions in their own right.

It follows from all this that child and adolescent psychiatric disorder must be considered within a (demystified) family-systems approach, not just isolated as a disorder within the individual child".

Next, brief case descriptions can show how serious and distressing these 'predicaments' can be, even though they are not usually biomedical or lifethreatening situations. We emphasise how people can anyway be high users of medical services in various ways, just because they are desperate, or sure the 